\title{
MEMBANGUN GAME FUN ANIMAL PUZZLE MENGGUNAKAN ALGORITMA SHUFFLE RANDOM
}

\author{
Amelia Yusnita ${ }^{1)}$, Andi Yushika Rangan ${ }^{2)}$ Fery Setiawan ${ }^{3)}$ \\ ${ }^{1}$ Sistem Informasi, STMIK Widya Cipta Dharma \\ ${ }^{2,3}$ Teknik Informatika, STMIK Widya Cipta Dharma \\ ${ }_{1,2,3}$ Jl. M. Yamin No.25, Samarinda, 75123 \\ E-mail : qonita23@yahoo.com ${ }^{1)}$, andi.yushika@yahoo.com ${ }^{2)}$, ferstwn@gmail.com ${ }^{3)}$
}

\begin{abstract}
ABSTRAK
Game adalah salah satu implementasi bidang ilmu komputer yang perkembangannya sudah sangat pesat. Game juga merupakan bentuk aplikasi yang edukatif, artinya bisa dijadikan sebagai media pembelajaran dimana prosesnya bisa dilakukan dengan konsep belajar sambil bermain untuk anak-anak. Fun Animal Puzzle adalah permainan berjenis Drag and Drop Puzzle dan Match-Up Puzzle yang dirancang untuk mengasah ketepatan dan daya ingat anak. Dalam permainan ini pemain harus memasangkan potongan gambar yang sama dan mencocokkan dua gambar yang sama, pemain harus mengingat posisi gambar yang akan dicocokkan.

Dalam penelitian ini metode yang digunakan untuk merancang perangkat lunak adalah metode pengembangan multimedia yang terdiri dari concept, design, material collecting, assembly, testing, dan distribution. Algoritma yang digunakan adalah pengacakan shuffle dimana pemain tidak dapat menghapal posisi gambar bermain dan membuat permainan tidak membosankan serta mampu menerapkan sistem belajar sambil bermain dan menjadi metode pembelajaran yang baik di kalangan anak-anak. dengan tujuan memberikan proses pembelajaran yang baik dan efektif. penelitian ini diharapkan dapat meningkatkan ketangkasan dan imajinasi anak.
\end{abstract}

Adapun hasil akhir dari penelitian ini adalah dengan adanya game ini dapat membantu untuk belajar mengingat, sehingga dapat melatih daya nalar dan daya ingat serta dapat digunakan sebagai sarana hiburan.

Kata Kunci: Game Puzzle ,Fun Animal Puzzle, SwishMax

\section{PENDAHULUAN}

Game atau permainan merupakan salah satu Permainan merupakan salah satu faktor yang cukup penting dalam tumbuh kembang anak. Pemanfaatan dan penggunaan game puzzle dapat menunjang proses pembelajaran terhadap anak. Pembelajaran dengan menggunakan game puzzle dapat mempermudah anak untuk berpikir, serta anak pun merasa memiliki kesenangan tersendiri, sehingga membutuhkan pemikiran yang lebih besar dapat diasah. Permainan yang membuat anak senang dengan alat peraga dapat meningkatkan kreatifitas anak dalam belajar merangkai atau mencocokan gambar (Hidayat, 2013).

Perkembangan permainan saat ini memang sangat populer, bukan hanya dari segi permainan, grafik, serta efek-efek yang sangat bagus. Namun saat ini sudah banyak dikembangkan permainan pembelajaran untuk menarik minat belajar pada anak mulai dari permainan pertualangan sampai dangan permainan puzzle.

Bermain memberikan kesempatan pada anak untuk langsung berperan dalam proses belajarnya dan sekaligus membuat anak merasa kompeten tentang kemampuan mereka untuk belajar. Fun Animal Puzzle adalah permainan yang dirancang dan dibuat untuk merangsang daya pikir anak dan melatih memecahkan masalah.

Berdasarkan pemaparan diatas maka diambil judul skripsi Membangun Game Fun Animal Puzzle menggunakan Algoritma Shuffle Random. Game Puzzle ini menggunakan logika pengacakan shuffle agar pemain tidak dapat menghapal posisi puzzle bermain dan membuat permainan tidak membosankan serta dapat menambah wawasan anak tentang nama-nama hewan serta bentuk dan ciri-cirinya.

\section{RUANG LINGKUP PENELITIAN}

Dalam penelitian ini permasalahan mencakup:

1. Permainan ini dibangun dengan menggunakan Swish Max 4.

2. Game ini adalah Game Offline dan bersifat single player.

3. Game ini dimainkan di $P C$ atau laptop.

4. Algoritma yang digunakan adalah Algoritma Shuffle Random.

5. Terdapat dua jenis puzzle yaitu drag and drop puzzle dan matching puzzle.

6. Terdapat bintang sebagai score setiap menyelesaikan satu level. 
7. Terdapat waktu untuk menyelesaikan permainan di setiap level.

8. Metode pengujian menggunakan BlackBox dan WhiteBox.

\section{BAHAN DAN METODE}

Dalam penelitian ini diperlukan suatu konsep dalam merumuskan definisi yang menunjang kegiatan penelitian, baik teori dasar maupun teori umum.

\subsection{Permainan (Game)}

Menurut Kimpraswil, dalam Muhammad (2009), mengatakan bahwa definisi permainan adalah usaha olah diri (olah pikiran dan olah fisik) yang sangat bermanfaat bagi peningkatan dan pengembangan motivasi, kinerja, dan prestasi dalam melaksanakan tugas dan kepentingan organisasi dengan lebih baik. Lain halnya dengan Joan Freeman dan Utami munandar, dalam Ismail (2009), mendefinisikan prmainan sebagai suatu aktifitas yang membantu anak mencapai perkembanganyang utuh, baik fisik, intelektual, sosial, moral, dan emosional.

Sedangkan menurut Anggra (2008), game atau permainan adalah sesuatu yang dapat dimainkan dengan aturan tertentu sehingga ada yang menang dan ada yang kalah, biasanya dalam konteks tidak serius dengan tujuag refreshing. Bermain game dapat dikatakan sebagai life style masyarakat dimasa kini. Mulai dari usia anak-anak hingga orang dewasa pun menyukai video game. Itu semua dikarenkan bermain video game adalah hal yang menyenangkan.

\subsection{Algoritma Logika Pengacakkan Shuffle}

Menurut Reza Andrea, (2015), Shuffle random adalah pengacakan urutan indeks dari sebuah record atau array. Pengacakan ini diibaratkan pengocokan pada dek kartu, dimana semua kartu dikocok sehingga susunannya teracak [4]. Contoh lain misalkan A adalah array $5 \times 1, \mathrm{~A}=\left[\begin{array}{lllll}1 & 2 & 3 & 4 & 5\end{array}\right]$ maka proses shuffle random akan mengacak susunan indek dari array $\mathrm{A}$ menjadi $\mathrm{A} 1=\left[\begin{array}{lllll}5 & 1 & 3 & 2 & 4\end{array}\right]$ ataupun menjadi susunan array yang lain. Dalam bahasa pemrograman fungsi shuffle random tidak hanya dapat mengacak angka, tetapi juga dapat mengacak array string ataupun campuran string dan angka.

\subsection{Tahapan Pengembangan Multimedia}

Menurut Binanto (2010), metodologi pengembangan multimedia terdiri dari enam tahap, yaitu concept (pengonsepan), design (pendesainan), meterial collecting (pengumpulan materi), assembly (pembuatan), testing (pengujian), dan distribution (pendistribusian). Keenam tahap ini tidak dapat bertukar posisi.Meski pun begitu, tahap concept memang harus menjadi hal yang pertama kali dikerjakan.

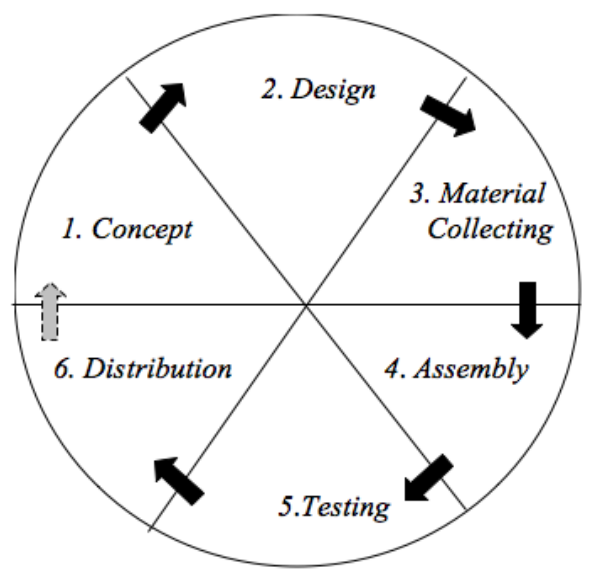

Gambar 1. Tahapan Pengembangan Multimedia

Berikut adalah tahapan pengembangan multimedia yang merupakan penjelasan dari gambar 1 :

\section{Concept}

Tahapan concept (pengonsepan) adalah tahap untuk menentukan tujuan dan siapa pengguna program (indentifikasi audiens). Tujuan dan penguna akhir program berpengaruh pada nuansa multimedia sebagai pencerminan dari indentitas organisasi yang menginginkan informasi sampai pada pengguna akhir.Karakteristik pengguna termasuk kemampuan pengguna juga perlu dipertimbangkan karena dapat memengaruhi pembuatan desain.

Selain itu, tahap ini juga akan menentukan jenis aplikasi (presentasi, interaktif, dan lain-lain) dan tujuan aplikasi (hiburan, pelatihan, pembelajaran dan lain-lain). Dasar aturan untuk perancangan juga ditentukan pada tahap ini, misalnya ukuran aplikasi, target, dan lain-lain.Output dari tahap ini biasanya berupa dokumen yang bersifat naratif untuk mengungkapkan tujuan projek yang ingin dicapai.

2. Design

Design (perancangan) adalah tahap pembuatan spesifikasi mengenai arsitektur program, gaya, tampilan, dan kebutuhan material/bahan untuk program. Spesifikasi dibuat serinci mungkin sehingga pada tahap berikutnya, yaitu material collecting dan assembly, pengambil keputusan baru tidak diperlukan lagi, cukup menggunakan keputusan yang sudah ditentukan pada tahap ini. Meskipun demikian, pada prakteknya, pekerjaan proyek pada tahap awal masih akan sering mengalami penambahan bahan atau pengurangan bagian aplikasi, atau perubahan-perubahan lain.

3. Material Collecting

Material Collecting adalah tahap pengumpulan bahan yang sesaui dengan kebutuhan yang dikerjakan. Bahan-bahan tersebut, antara lain gambar clip art, foto, animasi, video, audio, dan lain-lain yang dapat diperoleh secara geratis atau dengan pemesanan kepada pihak lain sesuai dengan rancangannya.Tahap ini dapat dikerjakan secara paralel dengan tahap assembly. Namun, pada beberapa kasus, tahap material collecting dan tahap 
assembly akan dikerjakan secara linear dan tidak paralel.

4. Assembly

Tahap Assembly adalah tahap pembuatan semua objek atau bahan multimedia. Pembuatan aplikasi didasarkan pada tahap design, seperti storyboard, bagan alir, dan /atau struktur navigasi.

5. Testing

Tahap Testing (pengujian) dilakukan setelah menyelesaikan tahap pembuatan (assembly) dengan menjalankan aplikasi/program dan melihatnya apakah ada kesalahan atau tidak.Tahap pertama pada tahap ini disebut tahap pengujian alpha (alpha test) yang pengujiannya dilakukan oleh pembuat atau lingkungan pembuatnya sendiri. Setelah lolos dari pengujian alpha, pengujian beta yang melibatkan penggunaan akhir akan di lakukan.

\section{Distribution}

Pada tahap ini, aplikasi akan disimpan dalam suatu media penyimpanan. Jika media penyimpanan tidak cukup untuk menampung aplikasinya, komprensi terhadap aplikasi tersebut akan dilakukan.Tahap ini juga dapat disebut tahap evaluasi untuk pengembangan produk yang sudah jadi supaya menjadi lebih baik. Hasil evaluasi ini dapat digunakan sebagai masukkan untuk tahap concept pada produk selajutnya

\section{RANCANGAN APLIKASI}

Berikut adalah rancangan dari aplikasi game yang dibangun:

\section{Use Case Diagram Game Fun Animal Puzzle}

Berikut ini merupakan use case diagram Perancangan Game Fun Animal Puzzle dapat dilihat pada gambar 2 :

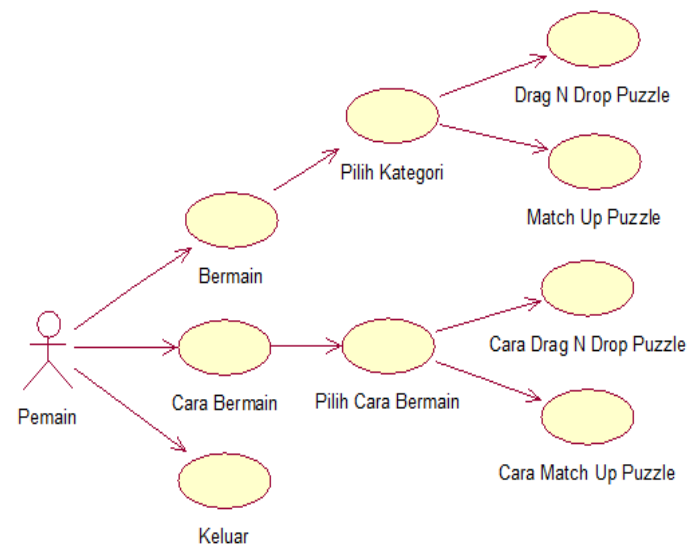

\section{Gambar 2. Use Case Diagram Game Fun Animal Puzzle}

Pada gambar 2 dapat dilihat bahwa pemain dapat melakukan beberapa aksi sebelum memulai permainan. Dalam menu utama pemain dapat memilih "Bermain" dan terdapat menu "Pilih Kategori" yang berisi pilihan "Drag N Drop Puzzle"dan "Match Up Puzzle", "Cara Bermain" dan terdapat menu "Pilih Cara Bermain" yang berisi pilihan "Cara Drag N Drop Puzzle"dan "Cara Match Up Puzzle", selanjutnya "Keluar" untuk mengakhiri permainan.

\section{Activity Diagram Game Fun Animal Puzzle}

Berikut ini merupakan gambar Activity Diagram pada Game Fun Animal Puzzle dapat dilihat pada gambar 3:

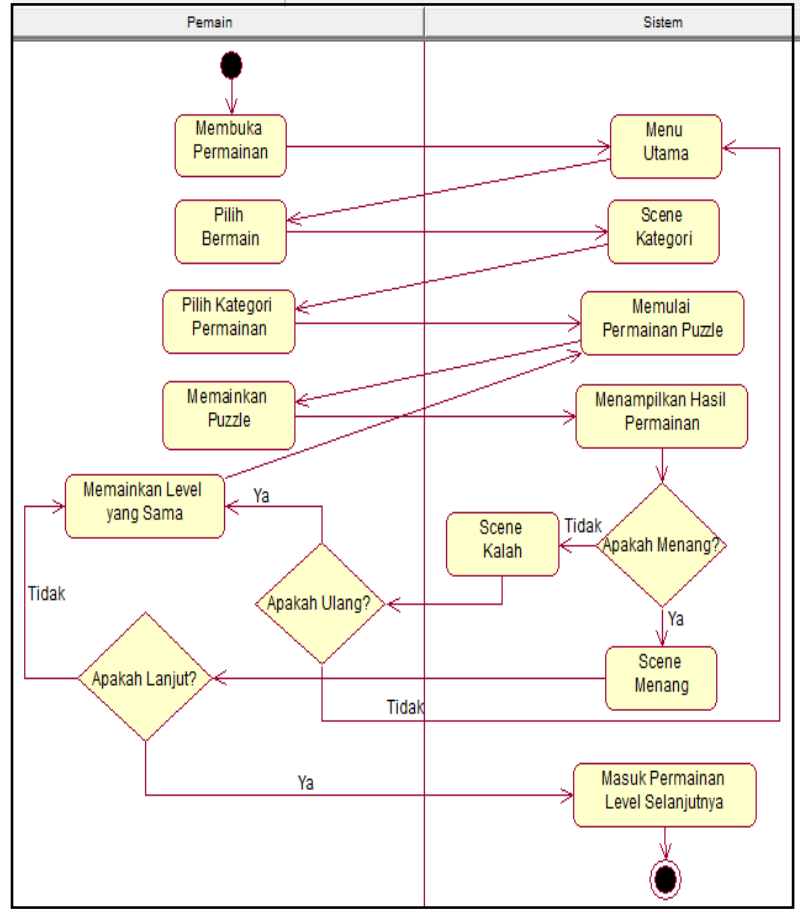

Gambar 3. Activity Diagram untuk pada Game Fun Animal Puzzle

Pada gambar 3 dijelaskan alur aktifitas yang terjadi disaat pemain membuka permainan kemudian memilih "Bermain" pada menu utama sampai pemain menyelesaikan permainan. Sistem akan menampilkan menu utama dimana pemain memilih "Bermain" untuk memulai permainan, kemudian sistem akan menampilkan menu "Pilih Kategori".

Selanjutnya pemain memainkan permainan tersebut, dan sistem akan menampilkan hasil dari permainan disaat permainan tersebut telah berakhir. Saat pemain gagal atau kalah pada permainan tersebut, sistem akan menampilkan sebuah scene "Kalah", di dalam scene kalah ditampilkan dua pilihan yakni untuk "Main Lagi" atau "Kembali" ke menu utama permainan.

Jika pemain memilih "Main Lagi" maka sistem akan mengulang kembali permainan yang sama, dan jika pemain memilih "Kembali" maka sistem akan menampilkan kembali menu utama permainan. Jika pemain berhasil memenangkan permainan tersebut, sistem akan menampilkan sebuah scene "Menang" yang memiliki dua pilihan yaitu "Main Lagi" dan "Lanjut". Pemain dapat memilih "Main Lagi" untuk memainkan permainan yang sama, dan memilih "Lanjut" untuk memulai permainan level selanjutnya. 


\section{Sequence Diagram Game Fun Animal Puzzle}

Berikut ini merupakan gambar Sequence Diagram Game Fun Animal Puzzle dapat dilihat pada gambar 4:

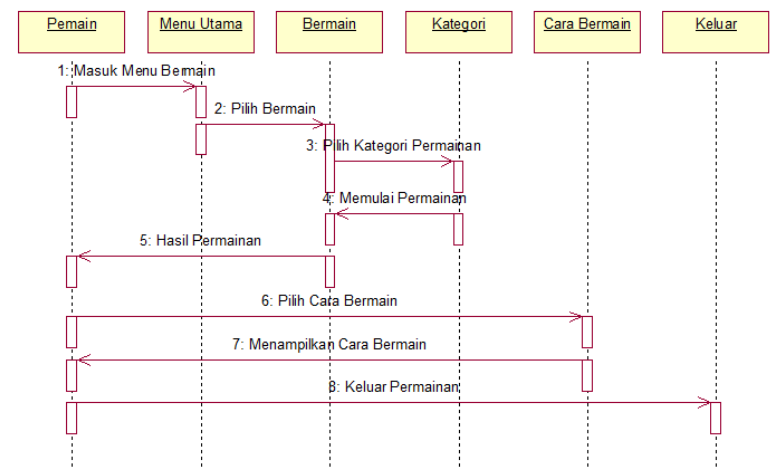

Gambar 4. Sequence Diagram Game Fun Animal Puzzle

Gambar 4 menunjukkan proses yang terjadi antara pemain dengan sistem, dimana sistem akan mengesekusi setiap proses permainan agar permainan dapat berjalan sesuai dengan semestinya.

\section{IMPLEMENTASI}

Pada Game ini terdapat dua jenis permainan puzzle yang bisa dimainkan, yaitu Drag $n$ Drop Puzzle dan Match Up Puzzle. Pada permainan Drag $n$ Drop Puzzle, pemain diharuskan menyusun potongan gambar puzzle hingga terbentuk sebuah gambar yang utuh atau sempurna dengan waktu yang terbatas dan pada permainan Match Up Puzzle, pemain diharuskan menyamakan semua gambar puzzle yang ada dengan waktu yang terbatas.

\section{Tampilan Menu Utama}

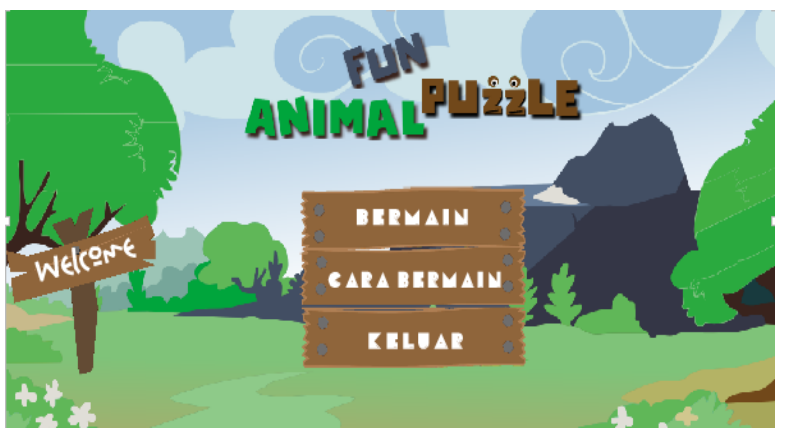

Gambar 5. Tampilan Menu Utama

Pada gambar 5 scene menu utama merupakan tampilan utama dari edugame disaat pemain baru memasuki sistem. terdapat nama atau judul dari Fun Animal Puzzle. Setiap tombol pada scene menu utama memiliki fungsi masing-masing yang menghubungkan satu scene dengan scene lainnya.

\section{Tampilan Menu Pilih Kategori}

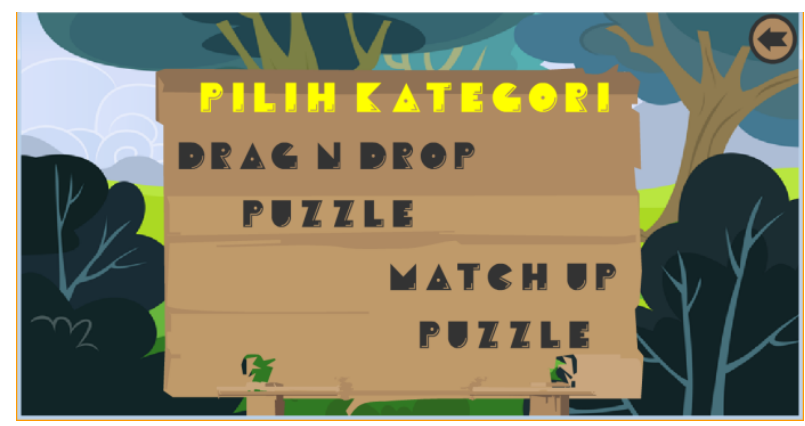

Gambar 6. Tampilan Menu Pilih Kategori

Pada gambar 6 Scene menu bermain adalah scene dimana pemain dapat memilih kategori jenis permainan yang ingin dimainkan. Terdapat dua pilihan kategori permainan yaitu Drag $N$ Drop Puzzle dan Match Up Puzzle.

\section{Scene Menu Drag n Drop Puzzle}

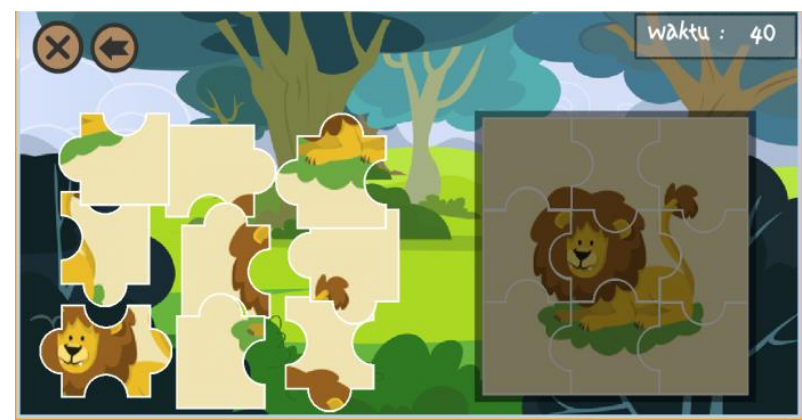

Gambar 7. Scene Menu Drag N Drop Puzzle

Pada gambar 7 scene menu Drag $n$ Drop Puzzle adalah scene dimana dimana pemain harus mencocokan potongan gambar dengan cara menarik potongan menggunakan cursor mouse menuju gambar potongan yang sama.

\section{Scene Menu Match Up Puzzle}

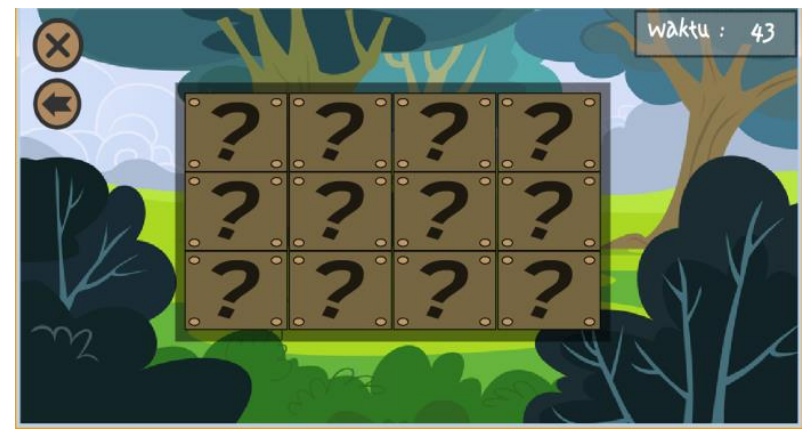

Gambar 8. Scene Menu Match Up Puzzle

Pada gambar 8 scene menu belajar huruf adalah scene dimana pemain harus mencocokan gambar dan menyelesaikan permainan dengan waktu yang terbatas. 
Pada gambar 11 scene menu cara bermain match up puzzle adalah scene dimana pemain dapat melihat cara bermain untuk match up puzzle.

\section{Scene Menu Pilih Cara Bermain}

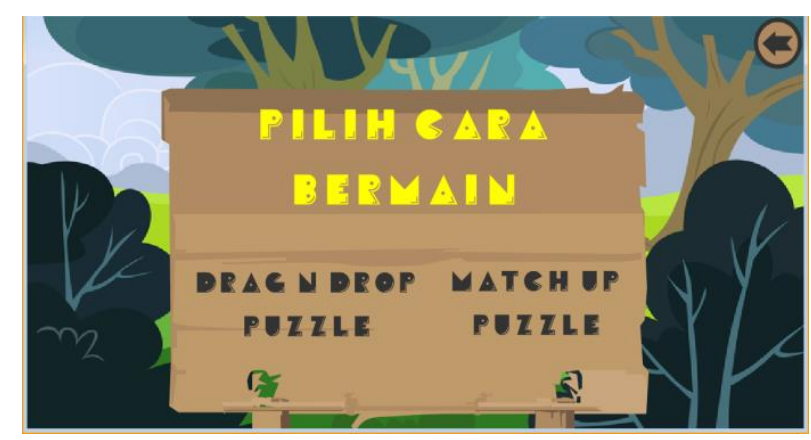

Gambar 9. Scene Menu Pilih Cara Bermain

Pada gambar 9 scene menu pilih cara bermain adalah scene dimana pemain memilih untuk melihat cara bermain. Terdapat dua pilihan cara bermain yaitu cara bermain Drag N Drop Puzzle dan cara bermain Match Up Puzzle.

\section{Scene Menu Cara Bermain Drag N Drop Puzzle}

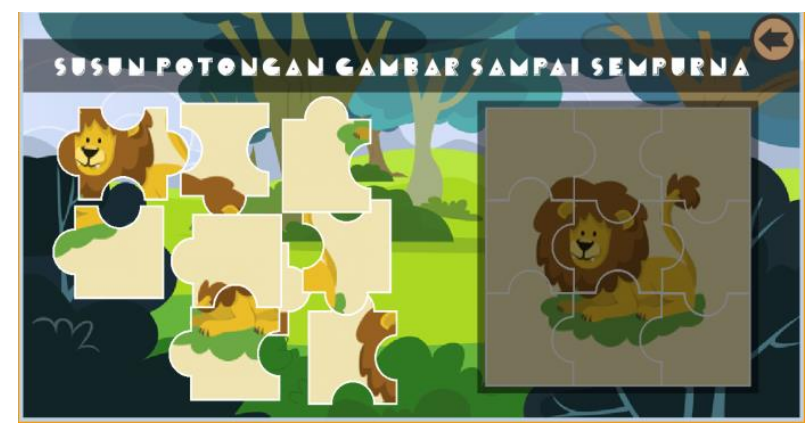

Gambar 10. Scene Menu Cara Bermain Drag $N$ Drop Puzzle

Pada gambar 10 scene menu cara bermain drag $n$ drop puzzle adalah scene dimana pemain dapat melihat cara bermain untuk drag $n$ drop puzzle.

\section{Scene Menu Cara Bermain Match Up Puzzle}

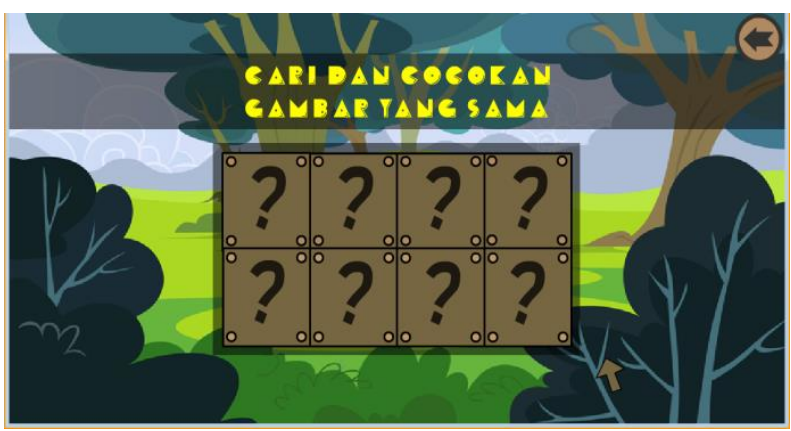

Gambar 11. Scene Menu Cara Bermain Match Up Puzzle

\section{Scene Menu Menang}

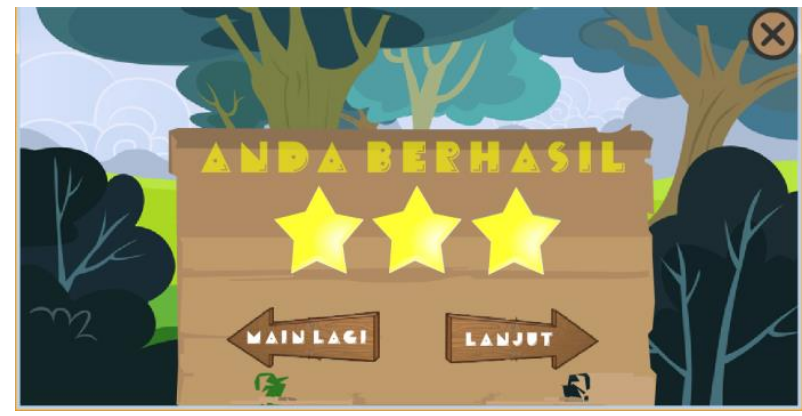

Gambar 12. Scene Menu Menang

Pada gambar 12 scene menu Menang adalah scene saat pemain berhasil menang pada setiap level. Terdapat Pilihan Main Lagi untuk mengulang permainan pada level yang sama dan Lanjut untuk melanjutkan permainan ke level selanjutnya.

\section{Scene Menu Kalah}

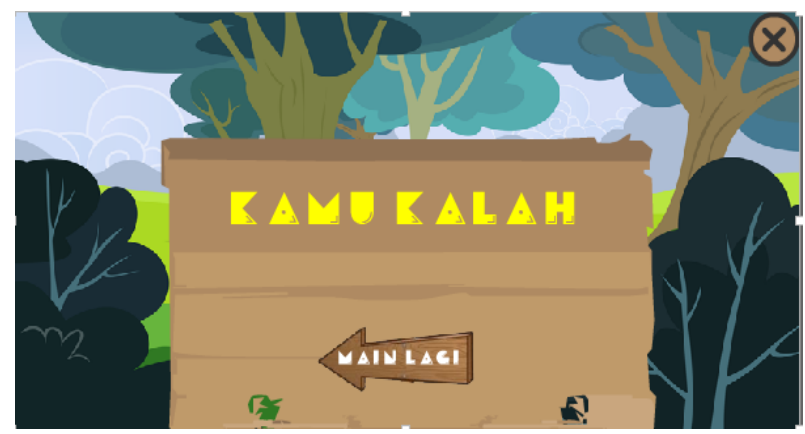

Gambar 13. Scene Menu Kalah

Pada gambar 13 scene Kalah adalah scene saat pemain tidak dapat menyelesaikan permainan. Terdapat pilihan Main Lagi untuk mengulang permainan pada level yang sama.

\section{KESIMPULAN}

Berdasarkan uraian dari masing- masing bab dan hasil pembahasan maka dapat disimpulkan bahwa pembuatan Fun Animal Puzzle sebagai berikut :

1. Pembuatan permainan Fun Animal Puzzle melalui proses demi proses, desain dan pembuatan animasi menggunakan program Swish Max4, setelah itu menjadi sebuah file berformat .SWF dan .EXE dapat dijalankan di PC.

2. Permainan Fun Animal Puzzle mengajarkan cara bermain menyusun puzzle.

3. Pengujian dalam game ini menggunakan pengujian Blackbox dan Whitebox. dengan demikian game ini dapat berjalan sesuai dengan aturannya.. 
4. Teknik pengacakan posisi awal menggunakan variabel Shuffle random agar pemain tidak dapat mengingat gambar puzzle.

\section{SARAN}

Berdasarkan hasil dari penelitian ini akan beberapa saran, yaitu sebagai berikut :

1. Permainan ini hanya menggunakan waktu sebagai tolak ukur keberhasilan dalam bermain, diharapkan ada pihak yang mampu mengembangkan permainan ini dengan menggunakan algoritma-algoritma yang lebih kompleks.

2. Permainan ini hanya berbasis game PC, diharapkan ada pihak yang mampu mengembangkan menjadi berbasis platform lainya selain PC atau Laptop.

\section{DAFTAR PUSTAKA}

Adnyana, 2011, Modul Swishmax, (http://ilmukomputer /files/Modul Swish Max tfn.doc), Diakses pada tanggal 23 Oktober 2014.

Andrea, Reza, 2015, Teknik Pengacakan Posisi Objek Permainan Match-Up "Find Me!-Bumi Etam", Prosiding Senaik 2015, Yogyakarta : P3M STMIK Amikom

Anggra, 2008, Memahami Teknik Dasar Pembuatan Game Berbasis Flash, Yogyakarta : Gava Media.

Binanto, Iwan, 2010, Multimedia Digital-Dasar Teori dan Pengembangannya, Yogyakarta: Andi

Hendratman, Hendi, 2008, The Magic of Adobe Photoshop, Bandung: Informatika

Hurd, Daniel dan Jenuings, Erin, 2009, Standardized Educational Games Ratings : Suggested Criteria, London : Longman

Ismail, Andang, 2009, Education Games, Yogyakarta : Pro-U Media

Kusna, Ra'uf Uzi, 2013, Pembuatan Game Memory Match 10 Menggunakan Adobe Flash, Jurusan Teknik Informatika, Yogyakarta : STMIK Amikom

Nugroho, Adi, 2005, Fokus Bangun Dasar Perancangan Sistem Dengan UML, Yogyakarta : Gramedia Pustaka Utama.

Pressman, Roger, S, 2010, Rekayasa Perangkat Lunak : Pendekatan Praktisi. Yogyakarta : Andi
Riyadi, Rahmad fajar, 2012, Game Memory Match Berbasis Android, Jurusan Teknik Informatika, Yogyakarta : STMIK Amikom

Setiawati, 2008, Education Games, Jakarta : Proumedia

Shalahuddin, Muhamad, 2011, Modul Pembelajaran : Rekayasa Perangkat Lunak (Terstruktur dan Berorientasi Objek), Bandung : Modula

Sidauruk, Acihmah, 2010, Pembuatan Game Matching Menggunakan Macromedia Flash 8, Jurusan Sistem Informasi, Yogyakarta : STMIK Amikom 